\title{
Production of curcuminoids by Escherichia coli carrying an artificial biosynthesis pathway
}

\author{
Yohei Katsuyama, Miku Matsuzawa, Nobutaka Funa \\ and Sueharu Horinouchi
}

\begin{abstract}
Correspondence
Sueharu Horinouchi

asuhori@mail.ecc.u-tokyo.ac.jp
\end{abstract}

Received 20 March 2008

Revised 29 May 2008

Accepted 15 June 2008

\begin{abstract}
Department of Biotechnology, Graduate School of Agriculture and Life Sciences, The University of Tokyo, Bunkyo-ku, Tokyo 113-8657, Japan
\end{abstract}

\begin{abstract}
Curcuminoids, which are produced specifically by plants of the order Zingiberales, have long been used as food additives because of their aromatic, stimulant and colouring properties and as traditional Asian medicines because of their anti-tumour, antioxidant and hepatoprotective activities. Curcuminoids are therefore attractive targets for metabolic engineering. An artificial curcuminoid biosynthetic pathway, including reactions of phenylalanine ammonia-lyase (PAL) from the yeast Rhodotorula rubra, 4-coumarate : CoA ligase (4CL) from Lithospermum erythrorhizon and curcuminoid synthase (CUS) from rice (Oryza sativa), a type III polyketide synthase, was constructed in Escherichia coli for the production of curcuminoids. Cultivation of the recombinant $E$. coli cells in the presence of tyrosine or phenylalanine, or both, led to production of bisdemethoxycurcumin, dicinnamoylmethane and cinnamoyl- $p$-coumaroylmethane. Another E. coli system carrying $4 C L$ and CUS genes was also used for high-yield production of curcuminoids from exogenously supplemented phenylpropanoid acids: $p$-coumaric acid, cinnamic acid and ferulic acid. The yields of curucminoids were up to $\sim 100 \mathrm{mg} \mathrm{I}^{-1}$. Furthermore, this system gave approximately $60 \mathrm{mg}$ curcumin $\mathrm{I}^{-1}$ from $10 \mathrm{~g}$ rice bran pitch, an industrial waste discharged during rice edible oil production, as a source of ferulic acid.
\end{abstract}

\section{INTRODUCTION}

Turmeric, produced from rhizomes of Curcuma longa L., has been widely used for centuries as a dietary spice and pigment and as a traditional Asian medicine for the treatment of various illnesses. Turmeric contains curcumin [1], demethoxycurcumin [2] and bisdemethoxycurcumin [3] as major curcuminoids (Fig. 1). Researches over the last few decades have shown that the medicinal properties of turmeric are attributable mainly to curcumin. Curcumin, which belongs chemically to a class of curcuminoids that are bis- $\alpha, \beta$-unsaturated $\beta$-diketones (Fig. 1), possesses various pharmacological effects, including anti-inflammatory, antioxidant, anticarcinogenic and antitumor activities (Duvoix et al., 2005; Sharma et al., 2005; Maheshwari et al., 2006; Anand et al., 2007). Recent clinical trials have demonstrated the efficacy of curcumin in various diseases, such as colorectal cancer and Alzheimer's disease (Shishodia et al., 2007). In addition, curcumin possesses

Abbreviations: APCIMS, atmospheric pressure chemical ionization mass spectrometry; 4CL, 4-coumarate:CoA ligase; COSY, homonuclear correlation spectroscopy; CUS, curcuminoid synthase from Oryza sativa; $\mathrm{HMBC}$, heteronuclear multiple-bond correlation; LC, liquid chromatography; MS, mass spectrometry; MS/MS, tandem mass spectrometry; $\mathrm{PAL}$, phenylalanine ammonia-lyase; PKS, polyketide synthase.

Three supplementary figures with additional spectrometric data on the curcuminoids are available with the online version of this paper. hepatoprotective activity on liver injury; Nanji et al. (2003), Bruck et al. (2007) and Muriel \& Rivera-Espinoza (2008) reported that curcumin prevents thioacetamide-induced liver fibrosis and alcohol-induced liver diseases. Despite the strong potential of curcumin in the prevention and cure of various diseases, the only natural source of curcuminoids is Curcuma species; curcuminoids and related compounds have been found exclusively in plants of the order Zingiberales.

Recent advances in metabolic engineering have made it possible to produce plant-specific polyketides, such as flavonoids and stilbenes, by employing non-plant organisms as hosts. For example, we designed an artificial biosynthesis pathway for production of flavonoids from tyrosine and phenylalanine by Escherichia coli, expressed it, and successfully produced naringenin from tyrosine and pinocembrin from phenylalanine (Hwang et al., 2003; Kaneko et al., 2003; Miyahisa et al., 2005). Watts et al. (2004) and Yan et al. (2005a) also reported metabolic engineering for production of flavonoids in E. coli. Furthermore, co-incubation of two microbial hosts, E. coli expressing the phenylpropanoid pathway and producing flavanones and Saccharomyces cerevisiae expressing isoflavone synthase, led to production of the isoflavone genistein (Katsuyama et al., 2007d). Jiang et al. (2005) and Yan et al. (2005b) reported the production of flavonoids by 

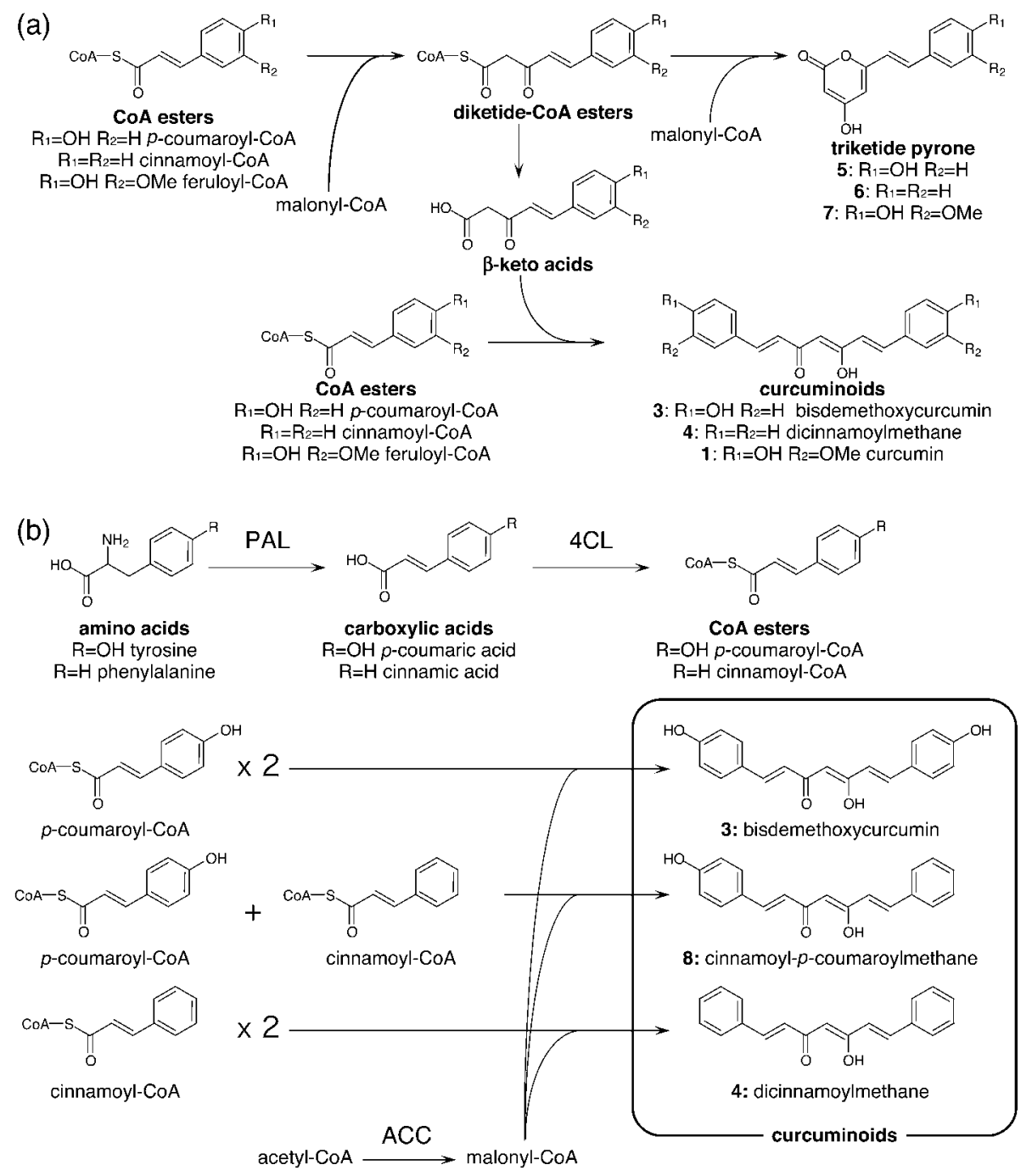

(c)
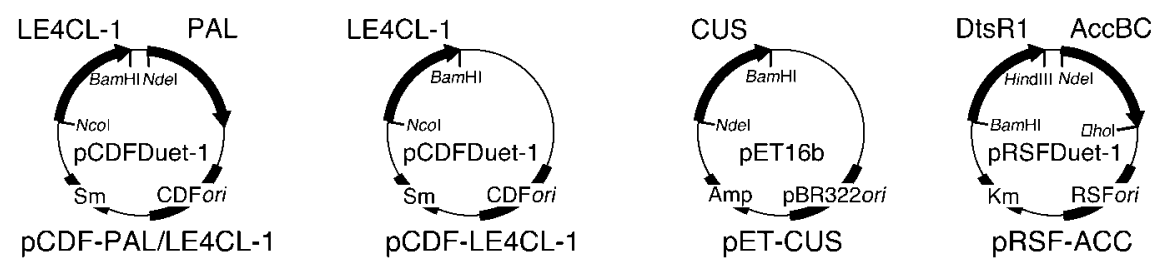

Fig. 1. Reaction catalysed by curcuminoid synthase (CUS) (a), biosynthesis routes of curcuminoids by recombinant $E$. coli (b), and the plasmids used in this study (c). (a) The CUS reaction begins with the thioesterification of the thiol moiety of Cys-174 by a starter molecule, a CoA ester. Decarboxylative condensation of the first extender substrate, malonyl-CoA, onto the thioester results in the formation of a diketide-CoA intermediate. Subsequent hydrolysis of the intermediate yields a $\beta$-keto acid, which in turn acts as the second extender substrate. The $\beta$-keto acid is then joined to the Cys-174-bound starter substrate by decarboxylative condensation to form curcuminoids [1], [3] and [4]. CUS also produces triketide pyrones [5] to [7] as byproducts. (b) The amino group of tyrosine and phenylalanine is removed by PAL to yield the corresponding carboxylic acids, which are then activated to the corresponding CoA esters by $4 \mathrm{CL}$. The CoA esters serve as a substrate of CUS and are converted into curcuminoids [3], [4] and [8]. Acetyl-CoA carboxylase (ACC), which catalyses conversion of acetyl-CoA into malonyl-CoA, is maintained in the E. coli cells carrying $P A L, 4 C L$ and CUS to increase the intracellular pool of malonyl-CoA. (c) PAL and LE4CL-1 on pCDF-PAL/LE4CL-1, CUS on pET-CUS and ACC on pRSF-ACC are all under the control of the IPTGinducible T7 promoter and a synthetic ribosome-binding sequence in the vectors. The selection markers on the vectors are resistance to streptomycin $(\mathrm{Sm})$, ampicillin $(\mathrm{Amp})$ and kanamycin $(\mathrm{Km})$. 
Saccharomyces cerevisiae. Resveratrol was also produced in micro-organisms and mammalian cells (Zhang et al., 2006; Beekwilder et al., 2006; Katsuyama et al., 2007a). Recently, Beekwilder et al. (2007) reported the production of a raspberry ketone by E. coli. The successful production of flavonoids and stilbenes depends on efficient expression of type III polyketide synthases (PKSs), responsible for the key step of extension and cyclization of polyketides to yield flavanone and stilbene skeletons in the respective organisms (Schröder, 1997; Austin \& Noel, 2003). We have improved the artificial pathways for the purpose of production of natural and 'unnatural' plant-specific polyketides, including flavonoids, isoflavones and stilbenes, and established a system in which, in principle, each of the three steps is carried on a plasmid: a substrate synthesis step for CoA ester synthesis from carboxylic acids by 4coumarate:CoA ligase; a polyketide synthesis step for conversion of the CoA esters into flavanones by chalcone synthases and chalcone isomerase and into stilbenes by stilbene synthase; and a modification step for modification of the flavanones and stilbenes by various modification enzymes (Katsuyama et al., 2007c). This system is useful and convenient in production of various polyketides by employing various combinations of enzyme genes at each step. In fact, 87 polyketides, including 36 unnatural flavonoids and stilbenes, were produced by recombinant E. coli cells containing various combinations of enzyme genes at the three steps (Katsuyama et al., 2007c).

We have recently identified a type III PKS, named CUS (curcuminoid synthase), that is capable of synthesis of curcuminoids from 4-coumaroyl-CoA and malonyl-CoA in a unique manner (Katsuyama et al., 2007b). The CUS type III PKS is from rice, Oryza sativa, which is phylogenetically distinct from Zingiberales. CUS catalyses the synthesis of bisdemethoxycurcumin [3] from two molecules of $p$ coumaroyl-CoA and one molecule of malonyl-CoA (Fig. 1a). CUS also accepts other phenylpropanoid-derived CoA esters, such as cinnamoyl-CoA and feruloyl-CoA, as a substrate to produce dicinnamoylmethane [4] and curcumin [1], respectively. In addition to curcuminoids, CUS produces triketide pyrones, [5] to [7], as by-products, by condensing two malonyl-CoAs to $p$-coumaroyl-CoA (Fig. 1a). The discovery of CUS prompted us to employ it as a type III PKS at the polyketide synthesis step in the artificial biosynthesis pathway for microbial production of plant-specific curcuminoids.

Here we describe the efficient production of curcuminoids by $E$. coli carrying an artificial biosynthesis pathway including CUS and enzymes of the phenylpropanoid pathway (Fig. 1b). Exogenous supplementation of tyrosine or phenylalanine, the precursors of the phenylpropanoid pathway, to the recombinant E. coli cells and incubation of them in minimal medium resulted in the production of curcuminoids, such as bisdemethoxycurcumin [3], dicinnamoylmethane [4], and cinnamoyl-p-coumaroylmethane [8]. Rice bran pitch, an industrial waste residue from production of rice edible oil, was also successfully used as a source of ferulic acid to yield curcumin.

\section{METHODS}

Materials. E. coli strains JM109 and BLR(DE3), plasmid pUC19, restriction enzymes, T4 DNA ligase, Taq DNA polymerase and other DNA-modifying enzymes were purchased from Takara Biochemicals. pET16b, pRSFDuet-1 and pCDFDuet-1 were purchased from Novagen. Rice bran pitch was a gift from Tsuno Food Industrial Co. Ltd (Wakayama, Japan). p-Coumaric acid was purchased from Aldrich. Tyrosine, phenylalanine, cinnamic acid and ferulic acid were purchased from Wako. Curcumin [1] was purchased from Sigma. Authentic bisdemethoxycurcumin [3] was purchased from ChromeDex. A triketide pyrone [5] derived from $p$-coumaroyl-CoA was prepared as described previously (Katsuyama et al., 2007b). pCDF-PAL/LE4CL-1 (Katsuyama et al., 2007a), pCDF-LE4CL-1 (Katsuyama et al., 2007c), pRSF-ACC (Miyahisa et al., 2005), and pET-CUS (Katsuyama et al., 2007b) were described previously. For the structures and the selection markers of these plasmids, see Fig. 1(c).

Production of curcuminoids by $\boldsymbol{E}$. coli. Ampicillin $\left(100 \mu \mathrm{g} \mathrm{ml}^{-1}\right)$, kanamycin $\left(50 \mu \mathrm{g} \mathrm{ml}^{-1}\right)$ and streptomycin $\left(50 \mu \mathrm{g} \mathrm{ml}^{-1}\right)$ were used when necessary. Recombinant E. coli BLR(DE3) cells were precultured overnight at $37^{\circ} \mathrm{C}$ in $2 \mathrm{ml}$ Luria-Bertani (LB) medium. The preculture was transferred into $100 \mathrm{ml} \mathrm{LB}$ medium and cultured at $26{ }^{\circ} \mathrm{C}$ until the $\mathrm{OD}_{600}$ reached 0.6. IPTG was then added at a final concentration of $1 \mathrm{mM}$ and the culture was continued for $5 \mathrm{~h}$. The cells were harvested by centrifugation and the cells ( $0.5 \mathrm{~g}$ wet weight) were suspended in $20 \mathrm{ml} \mathrm{M} 9$ or LB medium. To the cell suspension (25 $\mathrm{g} \mathrm{l}^{-1}$ wet weight) in $\mathrm{M} 9$ medium, $3 \mathrm{mM}$ each of amino acids (tyrosine and phenylalanine) or $1 \mathrm{mM}$ each of carboxylic acids, plus $40 \mathrm{~g}_{\text {glucose }} \mathrm{1}^{-1}, 25 \mathrm{~g} \mathrm{CaCO}_{3} \mathrm{1}^{-1}$, appropriate antibiotics and $1 \mathrm{mM}$ IPTG were added, and the culture was incubated at $26{ }^{\circ} \mathrm{C}$ for $60 \mathrm{~h}$. Then $2 \mathrm{ml}$ of the culture broth was taken and adjusted to $\mathrm{pH} 3.0$ with $6 \mathrm{M} \mathrm{HCl}$. After extraction with an equal volume of ethyl acetate, materials were concentrated by evaporation and dissolved in $100 \mu \mathrm{l}$ DMSO for HPLC and liquid chromatography-atmospheric pressure chemical ionization mass spectrometry (LC-APCIMS) analyses. LCAPCIMS in positive mode was performed on an Esquire Highcapacity Trap Plus (Bruker Daltonics) equipped with a PEGASIL-B $\mathrm{C}_{4}$ column $(4.6 \times 200 \mathrm{~mm}$; Senshu Scientific Co. $)$ and the sample was eluted with a gradient of acetonitrile in water (both containing $0.1 \%$ acetic acid) at a flow rate of $1 \mathrm{ml} \mathrm{min}^{-1}$. The conditions of the gradient were $10-100 \%$ acetonitrile for $45 \mathrm{~min}$. UV spectra were detected on an Agilent 1100 series UV detector. HPLC with a Senshu PEGASIL-B $\mathrm{C}_{4}$ reversed-phase HPLC column $(4.6 \times 250 \mathrm{~mm})$ was carried out on a Hitachi LaChrom ELITE system and the sample was eluted with a linear acetonitrile gradient $(10-100 \%$ over $45 \mathrm{~min})$ in water containing $0.1 \%$ trifluoroacetic acid at a flow rate of

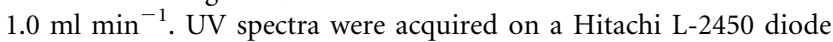
array detector. Commercially available curcumin [1] and NMR spectroscopically pure bisdemethoxycurcumin [3], cinnamoyl- $p$ coumaroylmethane [8], dicinnamoylmethane [4] and a triketide pyrone [5] derived from $p$-coumaroyl-CoA were used to prepare calibration curves.

Preparation of rice bran pitch medium. Rice bran pitch medium was prepared as described by Zheng et al. (2007). Briefly, $0.5 \mathrm{~g}$ rice bran pitch was dissolved in a solution containing $50 \mathrm{ml}$ each of $0.4 \mathrm{M}$ $\mathrm{NaOH}$ and ethanol, heated to $90{ }^{\circ} \mathrm{C}$, hydrolysed for $5 \mathrm{~h}$ and cooled to $4{ }^{\circ} \mathrm{C}$. After precipitates had been removed by filtration, the filtrate was evaporated to remove ethanol. To $40 \mathrm{ml}$ of the solution, $5 \mathrm{ml}$ sterilized $40 \%$ glucose, $5 \mathrm{ml}$ solution A $\left(6 \mathrm{~g} \mathrm{Na}_{2} \mathrm{HPO}_{4} \mathrm{l}^{-1}, 3 \mathrm{~g}\right.$ $\mathrm{KH}_{2} \mathrm{PO}_{4} \mathrm{l}^{-1}, 0.5 \mathrm{~g} \mathrm{NaCl} \mathrm{l}^{-1}$ and $\left.1 \mathrm{~g} \mathrm{NH}_{4} \mathrm{Cl} \mathrm{l}^{-1}\right), 50 \mu \mathrm{l} 1 \mathrm{M} \mathrm{MgSO}_{4}$ (final concentration, $1 \mathrm{mM}$ ), $50 \mu \mathrm{l} 100 \mathrm{mM} \mathrm{CaCl}_{2}$ (final, $0.1 \mathrm{mM}$ ), $50 \mu \mathrm{l} 100 \mathrm{mg}$ ampicillin $\mathrm{ml}^{-1}$ (final, $100 \mu \mathrm{g} \mathrm{ml}^{-1}$ ), $50 \mu \mathrm{l} 50 \mathrm{mg}$ kanamycin ml ${ }^{-1}$ (final, $50 \mu \mathrm{g} \mathrm{ml}^{-1}$ ), $50 \mu \mathrm{l} 50 \mathrm{mg}$ streptomycin $\mathrm{ml}^{-1}$ (final, $50 \mu \mathrm{g} \mathrm{ml}^{-1}$ ), and $50 \mu \mathrm{l} 1 \mathrm{M}$ IPTG (final, $1 \mathrm{mM}$ ) were added. 
The solution prepared in this way was used as a source of ferulic acid for curcumin production.

Structural elucidation of curcuminoids. Curcumin [1] was identified by comparing the retention time, UV spectra and MS/MS fragments with those of the authentic sample. Bisdemethoxycurcumin [3], cinnamoyl-p-coumaroylmethane [8] and dicinnamoylmethane [4] were identified by NMR spectroscopic studies and LC-APCIMS analysis. Each of the curcuminoids was prepared from a $200 \mathrm{ml}$-scale M9 culture as described above and purified by reversed-phase preparative HPLC. Bisdemethoxycurcumin [3] and cinnamoyl- $p$ coumaroylmethane [8] were purified by HPLC on an instrument equipped with a Senshu DOCOSIL-B $\mathrm{C}_{22}$ column $(20 \times 250 \mathrm{~mm})$ by elution with $30 \%$ and $90 \%$ acetonitrile, respectively, in water containing $0.1 \%$ trifluoroacetic acid. Dicinnamoylmethane [4] was purified by HPLC on an instrument equipped with a PEGASIL-B $\mathrm{C}_{4}$ column $(10 \times 250 \mathrm{~mm})$ by elution with $90 \%$ acetonitrile in water containing $0.1 \%$ trifluoroacetic acid. Spectroscopic data of the curcuminoids were as follows.

Bisdemethoxycurcumin [3]. ${ }^{1} \mathrm{H}$ NMR $\left(500 \mathrm{MHz}, \mathrm{CD}_{3} \mathrm{OD}\right): \delta=7.57$ $(\mathrm{d}, 2 \mathrm{H}, J=15.5 \mathrm{~Hz}), 7.48(\mathrm{~d}, 4 \mathrm{H}, J=8.5 \mathrm{~Hz}), 6.81(\mathrm{~d}, 4 \mathrm{H}, J=8.5 \mathrm{~Hz})$, $6.58(\mathrm{~d}, 2 \mathrm{H}, J=15.5 \mathrm{~Hz}), 5.94(\mathrm{~s}, 1 \mathrm{H})$. HPLC: $R_{\mathrm{t}}=26.0$. LC-APCIMS (positive): MS, $m / z 309[\mathrm{M}+\mathrm{H}]^{+}$, MS/MS (precursor ion at $\mathrm{m} / z$ 309), $m / z 147$ (47) $\left[\mathrm{C}_{9} \mathrm{H}_{7} \mathrm{O}_{2}\right]^{+} \mathrm{m} / z 225$ (100) $\left[\mathrm{M}+\mathrm{H}-\mathrm{C}_{4} \mathrm{H}_{4} \mathrm{O}_{2}\right]^{+}$. HRMS (ESI): found for $\left[\mathrm{C}_{19} \mathrm{H}_{16} \mathrm{O}_{4}+\mathrm{H}\right]^{+}, 309.11593$, calcd, 309.11268. UV: $\lambda_{\max } 417 \mathrm{~nm}$.

Cinnamoyl-p-coumaroylmethane [8]. ${ }^{1} \mathrm{H}$ NMR (500 $\left.\mathrm{MHz}, \mathrm{CDCl}_{3}\right)$ : $\delta=7.67(\mathrm{~d}, 1 \mathrm{H}, J=16 \mathrm{~Hz}), 7.64(\mathrm{~d}, 1 \mathrm{H}, J=16 \mathrm{~Hz}), 7.57(\mathrm{dd}, 2 \mathrm{H}, J=2$, $7.5 \mathrm{~Hz}), 7.49(\mathrm{~d}, 2 \mathrm{H}, J=8.5 \mathrm{~Hz}), 7.40(\mathrm{~m}, 3 \mathrm{H}), 6.87(\mathrm{~d}, 2 \mathrm{H}$, $J=8.5 \mathrm{~Hz}), 6.63(\mathrm{~d}, 1 \mathrm{H}, J=16 \mathrm{~Hz}), 6.52(\mathrm{~d}, 1 \mathrm{H}, J=16 \mathrm{~Hz}), 5.83(\mathrm{~s}$, 1H). HPLC: $R_{\mathrm{t}}=30.3$. LC-APCIMS (positive): MS, $m / z 293[\mathrm{M}+\mathrm{H}]^{+}$, MS/MS (precursor ion at $\mathrm{m} / z$ 293), $\mathrm{m} / z 131$ (17) $\left[\mathrm{C}_{9} \mathrm{H}_{7} \mathrm{O}_{1}\right]^{+} \mathrm{m} / z 147$ (26) $\left[\mathrm{C}_{9} \mathrm{H}_{7} \mathrm{O}_{2}\right]^{+} \mathrm{m} / z 209$ (100) $\left[\mathrm{M}+\mathrm{H}-\mathrm{C}_{4} \mathrm{H}_{4} \mathrm{O}_{2}\right]^{+}$. HRMS (ESI): found for $\left[\mathrm{C}_{19} \mathrm{H}_{16} \mathrm{O}_{3}+\mathrm{H}\right]^{+}, 293.11578$, calcd, 293.11777. UV: $\lambda_{\max }$ $404 \mathrm{~nm}$.

Dicinnamoylmethane [4]. ${ }^{1} \mathrm{H}$ NMR $\left(500 \mathrm{MHz}, \mathrm{CDCl}_{3}\right): \delta=7.68(\mathrm{~d}$, $2 \mathrm{H}, J=16 \mathrm{~Hz}), 7.57(\mathrm{dd}, 4 \mathrm{H}, J=2,7 \mathrm{~Hz}), 7.39(\mathrm{~m}, 6 \mathrm{H}), 6.65(\mathrm{~d}, 2 \mathrm{H}$, $J=16 \mathrm{~Hz}$ ), $5.87(\mathrm{~s}, 1 \mathrm{H})$. HPLC: $R_{\mathrm{t}}=35.5$. LC-APCIMS (positive): MS, $\mathrm{m} / z 277[\mathrm{M}+\mathrm{H}]^{+}, \mathrm{MS} / \mathrm{MS}$ (precursor ion at $\mathrm{m} / z 277$ ), $\mathrm{m} / z 131(100)$ $\left[\mathrm{C}_{9} \mathrm{H}_{7} \mathrm{O}_{1}\right]^{+} m / z 193(61)\left[\mathrm{M}+\mathrm{H}-\mathrm{C}_{4} \mathrm{H}_{4} \mathrm{O}_{2}\right]^{+}$. HRMS (ESI): found for $\left[\mathrm{C}_{19} \mathrm{H}_{16} \mathrm{O}_{2}+\mathrm{H}\right]^{+}, 277.11792$, calcd, 277.12285. UV: $\lambda_{\max } 390 \mathrm{~nm}$.

Curcumin [1]. HPLC: $R_{\mathrm{t}}=26.8$. LC-APCIMS (positive): MS, $\mathrm{m} / z 369$ $[\mathrm{M}+\mathrm{H}]^{+}$, MS/MS (precursor ion at $\mathrm{m} / \mathrm{z} 369$ ), $\mathrm{m} / \mathrm{z} 175$ (100) $\left[\mathrm{C}_{10} \mathrm{H}_{7} \mathrm{O}_{3}\right]^{+}, m / z 177(68)\left[\mathrm{C}_{10} \mathrm{H}_{9} \mathrm{O}_{3}\right]^{+} \mathrm{m} / z 245(91)\left[\mathrm{C}_{14} \mathrm{H}_{13} \mathrm{O}_{4}\right]^{+} \mathrm{m} / z$ $285(91)\left[\mathrm{M}+\mathrm{H}-\mathrm{C}_{4} \mathrm{H}_{4} \mathrm{O}_{2}\right]^{+}$. UV: $\lambda_{\max } 426 \mathrm{~nm}$.

Demethoxycurcumin [2]. HPLC: $R_{\mathrm{t}}=26.4$. LC-APCIMS (positive): MS, $m / z 339[\mathrm{M}+\mathrm{H}]^{+}$.

Cinnamoylferuloylmethane [9]. HPLC: $R_{\mathrm{t}}=31.1$. LC-APCIMS (positive): MS, $m / z 323[\mathrm{M}+\mathrm{H}]^{+}$.

The details of ${ }^{13} \mathrm{C}$-, homonuclear correlation spectroscopy (COSY)-, and heteronuclear multiple-bond correlation (HMBC)-NMR data, MS/MS spectra, and UV spectra are also described in Supplementary Figs S1, S2 and S3, available with the online version of this paper.

\section{RESULTS}

\section{Strategy for production of curcuminoids by $E$. coli}

We previously produced flavanones in E. coli harbouring an artificial two-step biosynthetic gene cluster, in which CoA ester synthesis as the first step and polyketide

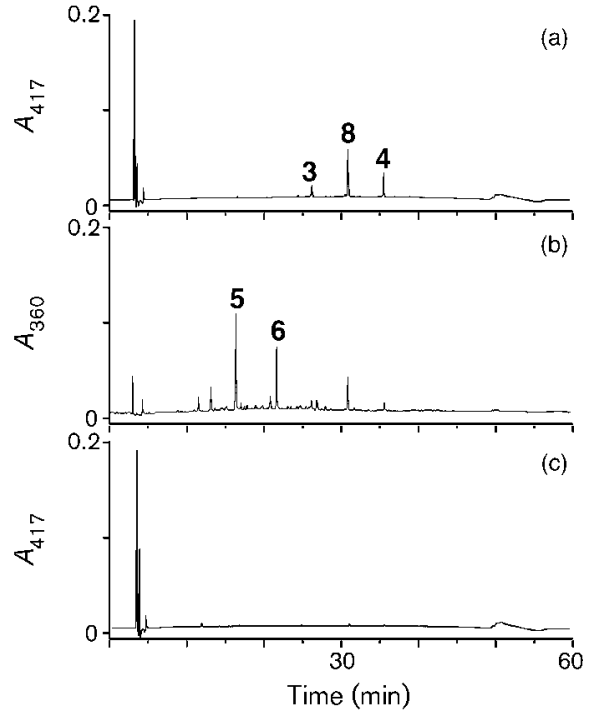

Fig. 2. HPLC analysis of curcuminoids produced by recombinant $E$. coli that had been incubated in LB medium. $E$. coli harbouring pCDF-PAL/LE4CL-1, pRSF-ACC and pET-CUS produced bisdemethoxycurcumin [3], p-coumaroylcinnamoylmethane [8] and dicinnamoylmethane [4] (a) and triketide pyrones, [5] derived from $p$-coumaric acid and [6] derived from cinnamic acid (b). E. coli harbouring pCDF-PAL/LE4CL-1, pRSF-ACC and pET16b (empty vector), as a negative control, produced no curcuminoids (c).

synthesis as the second step were combined (Hwang et al., 2003; Miyahisa et al., 2005). The gene cluster for the first step for the synthesis of CoA esters of tyrosine and phenylalanine consisted of $P A L$, encoding phenylalanine ammmonia-lyase (PAL), from the yeast Rhodotorula rubra and $4 C L(S C C C L)$, encoding 4-coumarate: CoA ligase (4CL), from Streptomyces coelicolor A3(2). The enzymes for the second step for the extension of the carbon chains by successive condensation with malonyl-CoA and cyclization of the resultant products to form flavanones consisted of chalcone synthase from liquorice (Glycyrrhiza echinata) and chalcone isomerase from a Pueraria plant. In this case, the four enzyme genes were each under the control of the T7 promoter and a synthetic ribosome-binding sequence and assembled on a single plasmid, $\mathrm{pET}-\mathrm{P}_{\mathrm{T} 7}-4 \mathrm{GS}$ (Hwang et al., 2003; Miyahisa et al., 2005, 2006). In addition to this plasmid, we also constructed plasmid pRSF-ACC, in which the acetyl-CoA carboxylase (ACC) genes from Corynebacterium glutamicum were placed under the control of the T7 promoter and the ribosome-binding sequence to increase the intracellular pool of malonyl-CoA in E. coli. The recombinant $E$. coli cells harbouring the two plasmids pET- $\mathrm{P}_{\mathrm{T} 7}-4 \mathrm{GS}$ and $\mathrm{pRSF}-\mathrm{ACC}$ produced naringenin from tyrosine and pinocembrin from phenylalanine. In the case of stilbene production by E. coli, on the other hand, the first step for the CoA ester synthesis from tyrosine and phenylalanine by PAL and 4CL and the second step for stilbene synthesis from the CoA esters by stilbene synthase 
were separately placed on different plasmids. Recombinant E. coli cells harbouring pRSF-PAL/LE4CL-1 containing PAL from $R$. rubra and 4CL (LE4CL-1) from the plant Lithospermum erythrorhizon, pET-STS containing the stilbene synthase gene from peanut (Arachis hypogaea) and pRSF-ACC produced stilbenes (Katsuyama et al., 2007a). The successful production of flavonoid and stilbene compounds by E. coli prompted us to design an artificial gene cluster and express it for the synthesis of curcuminoids in E. coli.

Our strategy to produce curcuminoids by E. coli on the basis of the catalytic properties of CUS is depicted in Fig. 1(b). This pathway included two steps: a substrate synthesis step for CoA ester synthesis from tyrosine and phenylalanine and a polyketide synthesis step for conversion of the CoA esters into curcuminoids by CUS. At the first step, PAL converts tyrosine and phenylalanine to the corresponding phenylpropanoid acids, $p$-coumaric acid and cinnamic acid, respectively, which are then activated to CoA esters by 4CL. The plasmid, pCDF-PAL/LE4CL-1, for the first step contained $P A L$ from $R$. rhodotorula and $4 C L$ from L. erythrorhizon, both of which were under the control of the T7 promoter and the ribosome-binding sequence in the vector pCDFDuet-1 (Fig. 1c). At the second step, CUS condenses two molecules of the CoA ester of the phenylpropanoid acid with one molecule of malonyl-CoA to produce curcuminoids. The plasmid, pET-CUS, for the second step contained the CUS gene under the control of the T7 promoter and the ribosomebinding sequence in the vector pET16b (Fig. 1c). Both plasmids and pRSF-ACC had different replication origins and different selective markers, thus being maintained in the same E. coli cell.

\section{Production of curcuminoids from tyrosine and phenylalanine}

Recombinant E. coli BLR(DE3) cells harbouring pRSFPAL/LE4CL-1, pRSF-ACC and pET-CUS were grown in LB medium supplemented with antibiotics to maintain the plasmids and with IPTG to induce the T7 promoter, and the cells were harvested by centrifugation. The harvested cells were suspended to give a concentration of $25 \mathrm{~g}$ wet weight cells per litre in LB medium supplemented with the antibiotics and IPTG and incubated at $26{ }^{\circ} \mathrm{C}$ for $60 \mathrm{~h}$. Under the incubation conditions, no increase in cell mass was observed, as was found for the production of flavonoids (Miyahisa et al., 2005) and stilbenes (Katsuyama et al., 2007a). The culture broth was extracted with ethyl acetate and the extract was analysed by HPLC. The HPLC analysis revealed production of three compounds [3, 4 and $\mathbf{8}]$ when detected by the absorbance at $417 \mathrm{~nm}$ and of two compounds [5 and 6] when detected at $360 \mathrm{~nm}$ (Fig. 2). The hydrophobic compounds [3, 4 and 8$]$ were purified and identified as bisdemethoxycurcumin [3], cinnamoyl-p-coumaroylmethane [8] and dicinnamoylmethane [4] by LC-MS/ MS and ${ }^{1} \mathrm{H}-,{ }^{13} \mathrm{C}-$, COSY- and HMBC-NMR analyses. The NMR spectra $\left({ }^{1} \mathrm{H},{ }^{13} \mathrm{C}, \mathrm{COSY}\right.$ and $\left.\mathrm{HMBC}\right)$ of the bisdemethoxycurcumin produced by $E$. coli were identical to those of the authentic sample. Similarly, compounds [5] and [6] were both identified as a triketide pyrone. Details of the spectrometric data are described in Methods and Supplementary Figs S1-S3. These findings showed that the recombinant E. coli cells successfully produced curcuminoids, as we had expected. Most of the curcuminoids were found in the cell (data not shown).

The yields of these compounds that were calculated on the basis of the calibration curves obtained with the commercially available and purified compounds are shown in Table 1. As a representative, the yield of the triketide pyrone derived from $p$-coumaric acid was determined. The yield of this triketide pyrone [5] $\left(22 \pm 7 \mathrm{mg} \mathrm{l}^{-1}\right)$ was greater than that $\left(\sim 6 \mathrm{mg} \mathrm{l}^{-1}\right)$ of the major curcuminoid [4] in this reaction. Previous study revealed that CUS changes the product ratio between curcuminoids and pyrones depending on the substrate concentrations (Katsuyama et al., 2007b). For instance, when the reaction was started with the concentration of p-coumaroyl-CoA 10-fold higher than that of malonyl-CoA, curcuminods became predominant as a product. The low yield of curcuminoids is therefore due to low concentrations of $p$-coumaroyl-CoA and cinnamoyl-CoA, derived from the endogenous tyrosine and phenylalanine, respectively, in the E. coli cell by the actions of PAL and 4CL.

Table 1. Yields of curcuminoids from amino acids

Curcuminoids were purified from the culture broth and cells of E. coli harbouring pCDF-PAL/LE4CL-1, pRSF-ACC and pET-CUS that had been incubated at $26{ }^{\circ} \mathrm{C}$ for $60 \mathrm{~h}$ in various media. The concentrations of tyrosine and phenylalanine added were $3 \mathrm{mM}$ each (Tyr, $543 \mathrm{mg} \mathrm{l}^{-1}$; Phe, $\left.495 \mathrm{mg}^{-1}\right)$. Data are presented as mean $\pm \mathrm{SD}(n=3)$; ND, not determined.

\begin{tabular}{|c|c|c|c|c|c|}
\hline \multirow[t]{2}{*}{ Medium } & \multicolumn{3}{|c|}{ Curcuminoids ( $\mathrm{mg} \mathrm{l}^{-1}$ ) } & \multirow{2}{*}{$\begin{array}{c}\text { Pyrone }\left(\mathrm{mg} \mathrm{l}^{-1}\right) \\
5\end{array}$} & \multirow{2}{*}{$\begin{array}{c}\text { Ratio } \\
\quad 5 / 3\end{array}$} \\
\hline & 3 & 8 & 4 & & \\
\hline LB & $1.04 \pm 0.16$ & $5.16 \pm 2.13$ & $6.43 \pm 3.93$ & $22 \pm 7$ & 21 \\
\hline M9+ Tyr & $53.4 \pm 1.3$ & $18.1 \pm 6.1$ & $2.72 \pm 0.68$ & $209 \pm 18$ & 3.9 \\
\hline M9+ Phe & trace & $7.86 \pm 2.08$ & $107 \pm 18$ & ND & ND \\
\hline M9+Tyr + Phe & $4.04 \pm 2.01$ & $19.2 \pm 6.1$ & $35.3 \pm 19.0$ & ND & ND \\
\hline
\end{tabular}


We then supplied the amino acids to increase the concentrations of $p$-coumaroyl-CoA and cinnamoyl-CoA to the recombinant $E$. coli cells in M9 minimal medium. The E. coli cells were incubated at $26{ }^{\circ} \mathrm{C}$ for $60 \mathrm{~h}$ in the presence of $3 \mathrm{mM}$ each of tyrosine $\left(543 \mathrm{mg} \mathrm{l}^{-1}\right)$ or phenylalanine $\left(495 \mathrm{mg} \mathrm{l}^{-1}\right)$, or both, plus glucose, antibiotics and IPTG in M9 minimal medium. No increase of the cell mass was observed, which was advantageous in purifying the products from the M9 medium containing only small amounts of contaminants and metabolites of the host cell. In addition, the cytotoxicity of the curcuminoids, if any, caused no detectable effects on the E. coli cells. In this process, the E. coli cell was a so-called enzyme bag containing a whole set for synthesis of curcuminoids. The exogenous supplementation of the amino acids markedly improved the yields of the curcuminoids and pyrones (Table 1). Supplementation of tyrosine and phenylalanine greatly enhanced the production of bisdemethoxycurcumin [3] and dicinnamoylmethane [4], respectively. When both phenylalanine and tyrosine were supplied, the predominant product was dicinnamoylmethane. Furthermore, the yield of dicinnamoylmethane from phenylalanine was greater than that of bisdemethoxycurcumin from tyrosine. Although CUS prefers $p$-coumaroyl-CoA as a substrate, approximately two times more in comparison to cinnamoyl-CoA (Katsuyama et al., 2007b), the yield of dicinnamoylmethane was greater than that of bisdemethoxycurcumin in all reactions. This may be caused by the different rates of incorporation of tyrosine and phenylalanine into the pathway, which results from the substrate preferences of PAL and 4CL.

Unexpectedly, large amounts of the triketide pyrones [5] and [6] were detected in each reaction, although we expected a decrease in the amounts of the pyrones by supplying excess amounts of the amino acids. We examined the yield of the triketide pyrone derived from $p$-coumaric acid in the tyrosine-supplemented reaction. The yield of the triketide pyrone [5] reached $209 \pm 18 \mathrm{mg}$
$1^{-1}$ and was greater than that of bisdemethoxycurcumin [3] (Table 1). This result suggests that supplementation of an excess of tyrosine increased the total amount of $p$ coumaroyl-CoA but that newly generated $p$-coumaroylCoA was consumed by CUS rather than being accumulated in the cell to exceed the concentration of malonyl-CoA. This idea was supported by the following observations. When the intracellular concentration of malonyl-CoA was decreased by omitting pRSF-ACC from the reaction system, the ratio of bisdemethoxycurcumin [3] (yield, $3 \mathrm{mg} \mathrm{l}^{-1}$ ) to the triketide pyrone [5] (yield, less than $0.1 \mathrm{mg} \mathrm{l}^{-1}$ ) was improved approximately 20 -fold, although the yield of bisdemethoxycurcumin [3] decreased more than 10 -fold.

\section{Production of curcuminoids from carboxylic acids}

We next tried to improve the yields of curcuminoids by directly supplying phenylpropanoid acids to E. coli cells carrying 4CL, CUS and ACC (Fig. 3), on the assumption that the removal of the PAL step converting the amino acids to the corresponding carboxylic acids would increase the $p$-coumaroyl-CoA concentration in the E. coli cell. The recombinant E. coli cells harbouring pCDF-LE4CL-1, pRSF-ACC and pET-CUS were incubated at $26{ }^{\circ} \mathrm{C}$ for $60 \mathrm{~h}$ in the presence of $1 \mathrm{mM}$ each of the phenylpropanoid acids ( $p$-coumaric acid, cinnamic acid or ferulic acid), glucose, antibiotics and IPTG in M9 minimal medium. The yields of curcuminoids are shown in Table 2. When $p$ coumaric acid was supplied, the yields of the triketide pyrone [5] and bisdemethoxycurcumin [3] were $11 \pm 4.6 \mathrm{mg} \mathrm{l}^{-1}$ and $91 \pm 23 \mathrm{mg} \mathrm{l}^{-1}$, respectively. In this reaction, the ratio of bisdemethoxycurcumin to triketide pyrone was improved: it was 200 -fold higher than in the reaction starting from tyrosine, probably due to an increase of the p-coumaroyl-CoA concentration in the E. coli cells.

As described above, the recombinant $E$. coli cells carrying $P A L, 4 C L, C U S$ and ACC produced an asymmetrical

(a)

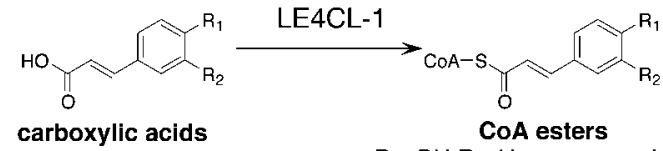

carboxylic acids

$\mathrm{R}_{1}=\mathrm{OH} \mathrm{R}_{2}=\mathrm{H} p$-coumaric acid

$\mathrm{R}_{1}=\mathrm{R}_{2}=\mathrm{H}$ cinnamic acid

$\mathrm{R}_{1}=\mathrm{OH} \mathrm{R}_{2}=\mathrm{OMe}$ ferulic acid
$\mathrm{R}_{1}=\mathrm{OH} \mathrm{R}_{2}=\mathrm{H}$ p-coumaroyl-CoA $\mathrm{R}_{1}=\mathrm{R}_{2}=\mathrm{H}$ cinnamoyl-CoA $\mathrm{R}_{1}=\mathrm{OH} \mathrm{R}_{2}=\mathrm{OMe}$ feruloyl-CoA
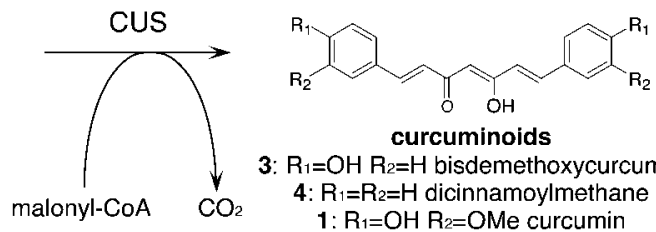

3: $\mathrm{R}_{1}=\mathrm{OH} \mathrm{R}_{2}=\mathrm{H}$ bisdemethoxycurcumin

4: $\mathrm{R}_{1}=\mathrm{R}_{2}=\mathrm{H}$ dicinnamoylmethane 1: $\mathrm{R}_{1}=\mathrm{OH} \mathrm{R}_{2}=\mathrm{OMe}$ curcumin

(b)

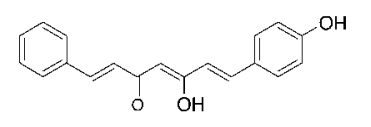

8: cinnamoyl-p-coumaroylmethane

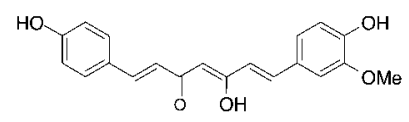

2: demethoxycurcumin

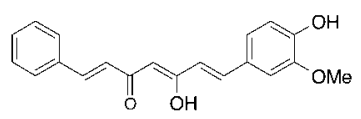

9: cinnamoylferuloylmethane

Fig. 3. Biosynthesis routes of curcuminoids from carboxylic acids (a) and structures of asymmetrical curcuminoids produced from combinations of two carboxylic acids (b). (a) By the sequential actions of $4 \mathrm{CL}$ and CUS, $p$-coumaric acid, cinnamic acid and ferulic acid are converted to symmetrical curcuminoids, bisdemethoxycurcumin [3], dicinnamoylmethane [4] and curcumin [1], respectively. (b) Structures of asymmetrical curcuminoids produced from combinations of two of the three carboxylic acids. 
Table 2. Yields of curcuminoids from carboxylic acids

Curcuminoids were purified from the culture broth and cells of E. coli harbouring pCDF-LE4CL-1, pRSF-ACC and pET-CUS that had been incubated at $26{ }^{\circ} \mathrm{C}$ for $60 \mathrm{~h}$ in various media. The concentrations of the carboxylic acids added were $1 \mathrm{mM}$ each ( $p$-coumaric acid, $164 \mathrm{mg} \mathrm{l}^{-1}$; cinnamic acid, $148 \mathrm{mg} \mathrm{ml}^{-1}$; ferulic acid, $\left.194 \mathrm{mg} \mathrm{l}^{-1}\right)$. Data are presented as mean $\pm \mathrm{SD}(n=3) ;-$, not detected.

\begin{tabular}{|lcccccc|}
\hline \multirow{2}{*}{ Medium } & \multicolumn{3}{c}{ Curcuminoids $\left(\mathbf{m g ~ l}^{-\mathbf{1}}\right)$} & & \multirow{2}{*}{ Pyrone $\left(\mathbf{m g ~ l}^{\mathbf{- 1}}\right)$} & Ratio \\
\cline { 2 - 4 } & $\mathbf{3}$ & $\mathbf{4}$ & $\mathbf{1}$ & $\mathbf{5}$ & $\mathbf{5 / 3}$ \\
\hline M9+ p-coumaric acid & $91 \pm 23$ & - & - & $11 \pm 4.6$ & 0.12 \\
M9+ cinnamic acid & - & $84 \pm 15$ & - & - & - \\
M9+ ferulic acid & - & - & $113 \pm 22$ & - & - \\
\hline
\end{tabular}

curcuminoid, cinnamoyl-p-coumaroylmethane [8], derived from cinnamic acid and $p$-coumaric acid; this is consistent with an in vitro study of CUS showing that it synthesizes asymmetrical curcuminoids from two starter substrates (Katsuyama et al., 2007b). Supplementation of both $p$ coumaric acid and cinnamic acid to E. coli cells harbouring pCDF-LE4CL-1, pRSF-ACC and pET-CUS led to production of cinnamoyl-p-coumaroylmethane [8]. Similarly, demethoxycurcumin [2] was produced from $p$-coumaric acid plus cinnamic acid, and cinnamoylferuloylmethane [9] was produced from cinnamic acid plus ferulic acid (data not shown). These compounds were purified and identified by LC-APCIMS analysis. Approximately $7 \mathrm{mg}^{-1}$ of cinnamoyl-p-coumaroylmethane [8] was produced from an equal amount of cinnamic acid $\left(1 \mathrm{mM}\right.$, or $\left.148 \mathrm{mg} \mathrm{l}^{-1}\right)$ plus p-coumaric acid $\left(1 \mathrm{mM}\right.$, or $\left.164 \mathrm{mg} \mathrm{l}^{-1}\right)$, but with simultaneous production of $90 \mathrm{mg}^{-1}$ of bisdemethoxycurcumin [3]. The production of the symmetrical curcuminoid was perhaps due to the preference of $p$-coumaric acid to cinnamic acid as a substrate of CUS. The yield of cinnamoylp-coumaroylmethane [8] might be improved by changing the substrate ratio of cinnamic acid to $p$-coumaric acid.

\section{Production of curcumin from rice bran pitch}

Rice bran pitch is a dark and viscous oil, which is discharged in the course of production of rice edible oil from rice bran (Taniguchi et al., 1999). Some ten million tonnes of brown rice is produced every year and $10 \%$ of its weight is polished away during production of white rice. This means that one million tonnes per year of rice bran is discharged. Approximately $40 \%$ of the rice bran is used to produce rice edible oil. Therefore, a large amount of rice bran pitch is discharged every year. Taniguchi et al. (1999) developed a method to extract ferulic acid from rice bran pitch through hydrolysis of $\gamma$-oryzanol by alkali. We therefore planned to make use of the ferulic acid in this rice waste as a substrate for the production of curcumin [1].

We first checked whether rice bran pitch could be used as a ferulic acid source in the above-described reaction to which ferulic acid was supplied. When rice bran pitch was directly added to M9 medium, E. coli harbouring pCDF-LE4CL-1, pRSF-ACC and pET-CUS produced only a trace amount of curcumin [1] $\left(0.68 \pm 0.37 \mathrm{mg} \mathrm{l}^{-1}\right.$ from approximately $10 \mathrm{~g}$ $1^{-1}$ of rice bran pitch). We assumed that most of the ferulic acid would be present as an esterified form, $\gamma$-oryzanol, that could not be used as a substrate for the system. In addition, the extraction of the products after incubation of the E. coli cells was complicated, due to the presence of oily material in the rice bran pitch. Therefore, we added a hydrolysis step to hydrolyse $\gamma$-oryzanol by alkali- and heattreatments, according to the method of Taniguchi et al. (1999). Indeed, the hydrolysis process diminished the viscosity of the oily material. The resultant rice bran pitch medium contained $1.1 \pm 0.15 \mathrm{mM}$ ferulic acid, as revealed by HPLC analysis, which showed that $11 \pm 1.4 \mathrm{mg}$ ferulic acid was extracted from $500 \mathrm{mg}$ rice bran pitch. E. coli cells (25 g wet weight $\mathrm{l}^{-1}$ ) harbouring pCDF-LE4CL-1, pRSFACC and pET-CUS and $25 \mathrm{~g} \mathrm{CaCO}_{3} \mathrm{l}^{-1}$ were added to the rice bran pitch medium, containing appropriate antibiotics and IPTG, and incubated at $26{ }^{\circ} \mathrm{C}$ for $60 \mathrm{~h}\left(\mathrm{CaCO}_{3}\right.$ was added to keep the $\mathrm{pH}$ of the medium slightly alkaline). In this reaction, $57 \pm 21 \mathrm{mg} \mathrm{l}^{-1}$ curcumin [1] was produced (Fig. 4). This means that about $60 \mathrm{mg}$ curcumin was produced from $10 \mathrm{~g}$ rice bran pitch.

\section{DISCUSSION}

The use of CUS from rice has opened up a way to produce Zingiberales-specific curcuminoids by bacteria. This is believed to be the first study demonstrating the production of curcuminoids in an organism other than Curcuma species. Starting with tyrosine and phenylalanine, this system converts the amino acids to the corresponding carboxylic acids by PAL, which are then converted to their CoA esters by 4 CL. CUS, as a key type III PKS in this artificial biosynthesis pathway, condenses the CoA ester with malonyl-CoA to yield curcuminoids at yields of 20 to $100 \mathrm{mg} \mathrm{l}^{-1}$. This system was modified and further used for production of asymmetrical curcuminoids, including cinnamoyl-p-coumaroylmethane [8] at a yield of $7 \mathrm{mg}$ $1^{-1}$, by simultaneously supplying two carboxylic acids. At present we cannot control the ratio of the curcuminoids produced by the modified system, because our knowledge of the catalytic properties, especially substrate specificity, of CUS is too incomplete. We expect that a better 


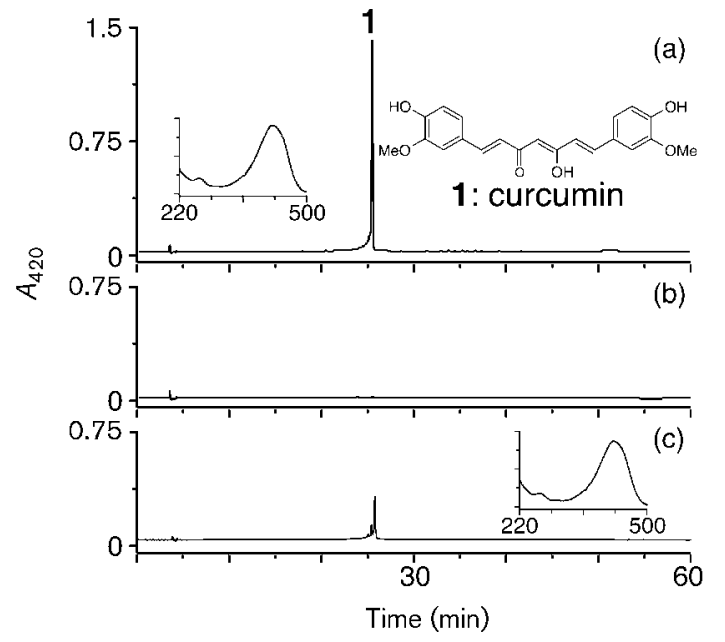

Fig. 4. HPLC analysis of curcumin produced by recombinant $E$. coli that had been incubated in rice bran pitch medium. $E$. coli harbouring pCDF-LE4CL-1, pRSF-ACC, and pET-CUS produced curcumin [1] (a), whereas E. coli harbouring pCDF-LE4CL-1, pRSF-ACC and pET16b (empty vector), as a negative control, produced no curcuminoids (b). The curcumin produced by $E$. coli was identified by comparing its UV spectrum and retention time with those of the authentic sample (c). The UV spectrum of the product and authentic curcumin are shown in the insets in (a) and (c), respectively.

understanding and engineering of CUS will much improve the yield of curcuminoids and the production ratio of a specific, desired compound. Furthermore, we expect that if the reaction was supplemented with other carboxylic acids, including unnatural compounds, these would be incorporated into the curcuminoid skeleton if the enzymes use them as a substrate, as we successfully synthesized natural and unnatural stilbenes by so-called precursor-directed biosynthesis (Katsuyama et al., 2007c).

In addition to curcuminoids, significant amounts of triketide pyrones were produced in all reactions. Efficient production of curcuminoids by CUS requires the CoA ester of a phenylpropanoid acid at a higher concentration than malonyl-CoA (Katsuyama et al., 2007b). We therefore assume that the concentration of CoA esters of phenylpropanoid acids in the reaction from the amino acids was too low to exclude the pyrone synthesis. In contrast, the yields of curcuminoids produced from the carboxylic acids reached $90-110 \mathrm{mgl}^{-1}$, at a molar yield of approximately $60 \%$. These results suggested that the reaction catalysed by LE4CL-1 was not a rate-limiting step but that probably the deamination catalysed by PAL was the rate-limiting step for producing $p$ coumaroyl-CoA in high yield. Therefore, addition of the amino acids to the culture caused no acceleration of the reaction generating $p$-coumaroyl-CoA by $\mathrm{PAL}$ and $4 \mathrm{CL}$ to overcome the reaction consuming $p$-coumaroyl-CoA by CUS.

Rice bran pitch is an abundant by-product or waste during rice edible oil production. A previous study reported that rice bran contains an array of bioactive compounds, such as oryzanols, phytic acid, ferulic acid and inositol hecaphosphate (Renuka Devi \& Arumughan, 2007). Zheng et al. (2007) reported microbial production of vanillin from ferulic acid, derived from waste residue of rice bran oil, by using Aspergillus niger and Pycnoporus cinnabarinus. Our present study also matches the trend of public requirements to make use of industrial wastes for the production of useful and valuable substances. The successful production of curcuminoids by recombinant E. coli is promising for production of various curcuminoid compounds, including 'unnatural' compounds, with various biological activities.

\section{ACKNOWLEDGEMENTS}

We thank Tsuno Food Industrial Co. Ltd for providing the rice bran pitch. Y. Katsuyama was supported by the Japan Society for Promotion of Science. This work was supported by the Research Grant Program 2005 of the New Energy and Industrial Technology Development Organization of Japan (05A07510d), a Grant-in Aid for Scientific Research on Priority Area 'Applied Genomics' from Monkasho, and an award fund of the Japan Society for Bioscience, Biotechnology, and Agrochemistry.

\section{REFERENCES}

Anand, P., Kunnumakkara, A. B., Newman, R. A. \& Aggarwal, B. B. (2007). Bioavailability of curcumin: problems and promises. Mol Pharm 4, 807-818.

Austin, M. B. \& Noel, J. P. (2003). The chalcone synthase superfamily of type III polyketide synthases. Nat Prod Rep 20, 79-110.

Beekwilder, J., Wolswinkel, R., Jonker, H., Hall, R., Ric de Vos, C. H. \& Bovy, A. (2006). Production of resveratrol in recombinant microorganisms. Appl Environ Microbiol 72, 5670-5672.

Beekwilder, J., van der Meer, I. M., Sibbesen, O., Broekgaarden, M., Qvist, I., Mikkelsen, J. D. \& Hall, R. D. (2007). Microbial production of natural raspberry ketone. Biotechnol J 2, 1270-1279.

Bruck, R., Ashkenazi, M., Weiss, S., Goldiner, I., Shapiro, H., Aeed, H., Genina, O., Helpern, Z. \& Pines, M. (2007). Prevention of liver cirrhosis in rats by curcumin. Liver Int 27, 373-383.

Duvoix, A., Blasius, R., Delhalle, S., Schnekenburger, M., Morceau, F., Henry, E., Dicato, M. \& Diederich, M. (2005). Chemopreventive and therapeutic effects of curcumin. Cancer Lett 223, 181-190.

Hwang, E. I., Kaneko, M., Ohnishi, Y. \& Horinouchi, S. (2003). Production of plant-specific flavanones by Escherichia coli containing an artificial gene cluster. Appl Environ Microbiol 69, 2699-2706.

Jiang, H., Wood, K. V. \& Morgan, J. A. (2005). Metabolic engineering of the phenylpropanoid pathway in Saccharomyces cerevisiae. Appl Environ Microbiol 71, 2962-2969.

Kaneko, M., Hwang, E. I., Ohnishi, Y. \& Horinouchi, S. (2003). Heterologous production of flavanones in Escherichia coli: potential for combinatorial biosynthesis of flavonoids in bacteria. J Ind Microbiol Biotechnol 30, 456-461.

Katsuyama, Y., Funa, N. \& Horinouchi, S. (2007a). Precursor-directed biosynthesis of stilbene methyl ethers in Escherichia coli. Biotechnol J 2, 1286-1293.

Katsuyama, Y., Matsuzawa, M., Funa, N. \& Horinouchi, S. (2007b). In vitro synthesis of curcuminoids by type III polyketide synthase from Oryza sativa. J Biol Chem 282, 37702-37709. 
Katsuyama, Y., Miyahisa, I., Funa, N. \& Horinouchi, S. (2007c). Synthesis of unnatural flavonoids and stilbenes by exploiting the plant biosynthetic pathway in Escherichia coli. Chem Biol 14, 613-621.

Katsuyama, Y., Miyahisa, I., Funa, N. \& Horinouchi, S. (2007d). Onepot synthesis of genistein from tyrosine by coincubation of genetically engineered Escherichia coli and Saccharomyces cerevisiae cells. Appl Microbiol Biotechnol 73, 1143-1149.

Maheshwari, R. K., Singh, A. K., Gaddipati, J. \& Srimal, R. C. (2006). Multiple biological activities of curcumin: a short review. Life Sci 78, 2081-2087.

Miyahisa, I., Kaneko, M., Funa, N., Kawasaki, H., Kojima, H., Ohnishi, Y. \& Horinouchi, S. (2005). Efficient production of (2S)-flavanones by Escherichia coli containing an artificial biosynthetic gene cluster. Appl Microbiol Biotechnol 68, 498-504.

Miyahisa, I., Funa, N., Ohnishi, Y., Martens, S., Moriguchi, T. \& Horinouchi, S. (2006). Combinatorial biosynthesis of flavones and flavonols in Escherichia coli. Appl Microbiol Biotechnol 71, 53-58.

Muriel, P. \& Rivera-Espinoza, Y. (2008). Beneficial drugs for liver disease. J Appl Toxicol 28, 93-103.

Nanji, A. A., Jokelainen, K., Tipoe, G. L., Rahemtulla, A., Thomas, P. \& Dannenberg, A. J. (2003). Curcumin prevents alcohol-induced liver disease in rats inhibiting the expression of NF- $\kappa \mathrm{B}$-dependent genes. Am J Physiol Gastrointest Liver Physiol 284, G321-G327.

Renuka Devi, R. \& Arumughan, C. (2007). Phytochemical characterization of defatted rice bran and optimization of a process for their extraction and enrichment. Bioresour Technol 98, 3037-3043.
Schröder, J. (1997). A family of plant-specific polyketide synthases: facts and predictions. Trends Plant Sci 2, 373-378.

Sharma, R. A., Gescher, A. J. \& Steward, W. P. (2005). Curcumin: the story so far. Eur J Cancer 41, 1955-1968.

Shishodia, S., Chaturvedi, M. M. \& Aggarwal, B. B. (2007). Role of curcumin in cancer therapy. Curr Probl Cancer 31, 243-305.

Taniguchi, H., Hosoda, A., Tsuno, T., Maruta, Y. \& Nomura, E. (1999). Preparation of ferulic acid and its application for the synthesis of cancer chemopreventive agents. Anticancer Res 19, 3757-3761.

Watts, K. T., Lee, P. C. \& Schmidt-Dannert, C. (2004). Exploring recombinant flavonoid biosynthesis in metabolically engineered Escherichia coli. Chembiochem 5, 500-507.

Yan, Y., Chemler, J., Huang, L., Martens, S. \& Koffas, M. A. G. (2005a). Metabolic engineering of anthocyanin biosynthesis in Escherichia coli. Appl Environ Microbiol 71, 3617-3623.

Yan, Y., Kohli, A. \& Koffas, M. A. G. (2005b). Biosynthesis of natural flavanones in Saccharomyces cerevisiae. Appl Environ Microbiol 71, 5610-5613.

Zhang, Y., Li, S.-Z., Li, J., Pan, X., Cahoon, R. E., Jaworski, J. G., Wang, X., Jez, J. M., Chen, F. \& Yu, O. (2006). Using unnatural protein fusions to engineer resveratrol biosynthesis in yeast and mammalian cells. J Am Chem Soc 128, 13030-13031.

Zheng, L., Zheng, P., Sun, Z., Bai, Y., Wang, J. \& Guo, X. (2007). Production of vanillin from waste residue of rice bran oil by Aspergillus niger and Pycnoporus cinnabarinus. Bioresour Technol 98, 1115-1119.

Edited by: W. Quax 